\title{
Article \\ Numerical Analysis of the Hydrogen Dispersion Behavior in Different Directions in a Naturally Ventilated Space
}

\author{
Xiaolu Zhang ${ }^{1,2}$, Qiubo Wang ${ }^{1}$, Xulei Hou ${ }^{1}$, Yuejuan $\mathrm{Li}^{1,2, *}$, Yang Miao ${ }^{1}{ }^{1}, \mathrm{Kun} \mathrm{Li}^{3}$ and Li Zhang ${ }^{3}$ \\ 1 Faculty of Materials and Manufacturing, Beijing University of Technology, Beijing 100124, China; \\ xiaolu.zhang@bjut.edu.cn (X.Z.); wangqiubo@emails.bjut.edu.cn (Q.W.); houxulei@emails.bjut.edu.cn (X.H.); \\ miaoyang@bjut.edu.cn (Y.M.) \\ 2 Engineering Research Center of Advanced Manufacturing Technology for Automotive Components, \\ Ministry of Education, Beijing University of Technology, Beijing 100124, China \\ 3 China Nuclear Power Technology Research Institute Co., Ltd, Shenzhen 518000, China; \\ k.li@cgnpc.com.cn (K.L.); zahngli@cggnnc.com.cn (L.Z.) \\ * Correspondence: yuejuan@bjut.edu.cn
}

check for

updates

Citation: Zhang, X.; Wang, Q.; Hou,

X.; Li, Y.; Miao, Y.; Li, K.; Zhang, L.

Numerical Analysis of the Hydrogen Dispersion Behavior in Different Directions in a Naturally Ventilated Space. Appl. Sci. 2021, 11, 615. https://doi.org/10.3390/app11020615

Received: 23 December 2020 Accepted: 8 January 2021

Published: 10 January 2021

Publisher's Note: MDPI stays neutral with regard to jurisdictional clai$\mathrm{ms}$ in published maps and institutional affiliations.

Copyright: () 2021 by the authors. Licensee MDPI, Basel, Switzerland. This article is an open access article distributed under the terms and conditions of the Creative Commons Attribution (CC BY) license (https:// creativecommons.org/licenses/by/ $4.0 /)$.

\begin{abstract}
Studies on hydrogen leakage have mainly focused on the influences of location and geometrical configuration on the distribution of the hydrogen in various spaces. The present study developed a simplified model for the leakage diffusion of hydrogen in an enclosed cuboid space with two vents, at the top and at the bottom, respectively. The effect of different leakage positions on the diffusion of the hydrogen was analyzed. The results showed that when hydrogen diffused vertically from the bottom to the top of the space, the farther the leakage position was from the vent on the side wall, the more hydrogen accumulated. When the hydrogen leaked in the vertical direction from the floor, the distance between the leakage position and the bottom vent had little effect on the horizontal diffusion speed of the hydrogen at the top of the space. The diffusion speed for the leakage in the horizontal direction was faster than that in the vertical direction. When the hydrogen leaked in the horizontal direction from the side wall, the height of the leakage had little effect on the horizontal diffusion speed of the hydrogen at the top of the space. Stratification occurred for models set up in the present study whenever the envelope of $1 \%$ mole fraction, or $4 \%$ mole fraction, of hydrogen extended to the whole ceiling.
\end{abstract}

Keywords: hydrogen leakage; natural ventilation; leakage position; diffusion

\section{Introduction}

Hydrogen has been widely utilized as a clean energy resource, and the hydrogen fuel cell bus is one of the key applications of hydrogen energy in transportation [1-3]. However, safety issues become more important due to the rapid flame speed of hydrogen and its high diffusion speed in air. Since hydrogen can burn in the air when the volume fraction of hydrogen reaches $4 \%$, factors such as ventilation, obstacles, green walls, and so on may significantly influence utilizations of hydrogen [4-6]. In reference to the ventilation method, the hydrogen fuel bus is generally simplified as a cuboid space with two vents at the top and the side wall, when investigating the concentration distribution of hydrogen with different ventilations $[7,8]$.

Since the leakage might occur at any position in the bus, a series of experimental studies were conducted to investigate the influence of the leakage position on the concentration distribution of hydrogen in spaces with fixed vents [9,10]. Pitts et al. [11] tested the hydrogen leakage in the vertical direction taking place at the center of the floor, and found the mole fraction of hydrogen above $2.6 \mathrm{~m}$ in the space reached about $29.3 \%$ (i.e., reaching the flammable concentration limit), which is higher than that at other altitudes $3500 \mathrm{~s}$ after the release. In another study with the same leakage position, Merio et al. [12] found stratification happened in the space with a relatively uniform combustible layer formed 
at the ceiling $20 \mathrm{~min}$ after the release. Helium was also used for experiments instead of hydrogen, due to safety concerns [13]. Compared to the leakage taking place on the floor, the average helium concentration was lower when the leakage height was $0.725 \mathrm{~m}$ in a cuboid space with two vents [14], and the stratification was more evident when the helium gas was injected from the top [15].

A number of numerical studies have been conducted to analyze the general process of hydrogen dispersion [16,17]. The behavior of a leakage from the bottom of a car was separated into two phases: the hydrogen firstly extending to the bottom of the car; and then rising to the ceiling of the parking garage [18]. It was also found that higher wind speed could accelerate the mixing of hydrogen and air, with the hydrogen composition decreasing faster [19]. Hwang et al. [20] found that hydrogen spread faster in spaces without any obstacles, than those with obstacles. Mohammad et al. [21] found the flammable region expanded when increasing the height of the leakage position for different leakage directions. Therefore, the effect of leakage direction on hydrogen diffusion needs to be further studied.

The concentration distribution of hydrogen for leakage in the vertical direction has also been investigated [22-25]. Matsuura et al. [8] found the velocity vectors varied when changing the positions of vents, with the leakage taking place in the vertical direction from the floor in a cuboid space. The mole fraction of the hydrogen was found to be higher than $4 \%$ in the area above $0.6 \mathrm{~m}$, and less than $2 \%$ in the area below $0.2 \mathrm{~m}$ from the floor after the stratification. The flow velocity also varied with different locations of both the leak and the vent when the leakage took place at the center of the floor in a prismatic cavity. The hydrogen concentration with the vent at the top of the space was lower than that when the vent was located in the lower half of the space [26]. Yao et al. [27] investigated a leakage taking place from the floor in a cuboid space and found a flow recirculation area existing between the leakage position and the vent in the wall. Li et al. [28] found the mole fraction increased as the height of the crossbeam increased for a leakage in the vertical direction in a cuboid space. The flammable region for the downward leakage disappeared much more rapidly than the upward leakage in the enclosure [21].

A leakage in the horizontal direction with leakage positions on a side wall in a cuboid space was also investigated. The hydrogen concentration was found to decrease with the increase of the distance between the leak and the vent [29]. Stefano et al. [30] found the average concentration of hydrogen increased with the increase of the height. A relatively higher concentration appeared in a short time near the corners of a cabin for different leakage positions [31]. Malakhov et al. [32] found that the flammable zone was larger in the space with ventilations than in a space without ventilations. The volume of a flammable gas cloud increased with the decrease of the distance between the leakage position and an obstacle [33].

Ventilation systems were required to ensure a maximum hydrogen mole fraction at $1 \%$ due to the lower flammability limit (LFL) of $4 \%$ vol (ISO 19880) [34]. Hussein et al. [35] investigated a hydrogen leakage in a naturally ventilated car park, and found the mole fraction of the hydrogen reached $1 \%$ after $20 \mathrm{~s}$ of the leakage. However, for a cuboid space with two vents, at both the top and the bottom walls, the diffusion of iso-surface of $1 \%$ mole fraction of hydrogen needs to be further explored [36]. The differences of hydrogen diffusion velocity for the specified space with different leakage positions were important for the utilization and layout of hydrogen sensors [37]. Yet the changes of hydrogen concentration and the flow state were often investigated in terms of the distribution of velocity and concentration.

Hydrogen sensors have often been used to monitor hydrogen concentration. Du et al. [38] developed a hydrogen-sensing material to optimize sensors' stability in monitoring hydrogen concentration rapidly in a wide low-temperature range. Hydrogen concentration was monitored at the corners of a cuboid space with two vents, with the leakage taking place at the floor. The concentration in the space, with the bottom vent near the ceiling, was found to be higher than other bottom vent positions [8]. Sensors were also set up at different heights in a cuboid space, with the leakage taking place at the center of 
the floor, and the hydrogen concentration at the top of the space was higher than that at other heights [39]. With helium sensors set up at different heights, the helium concentration at the top was greater than that at other heights [40]. Since the hydrogen diffusion was not isotropic and spreading evenly, the concentration in the space might not be accurately reflected by the monitoring points [41]. Therefore, the concentration of iso-surfaces could be used to study the diffusion of hydrogen comprehensively.

In the present study, a simplified model was developed to investigate the effect on hydrogen dispersion of leakage positions in a cuboid space with two vents. The influence of the leakage direction on the stratifications and diffusion velocity was also studied. In addition, the diffusion of the flammable area was analyzed with iso-surfaces of $4 \%$ mole fraction to advance the understanding of monitoring mechanisms.

\section{Methods}

\subsection{Problem Description}

In the computational domain, a simplified model of the fuel cell bus with the dimensions $L_{x}=2.9 \mathrm{~m}, L_{y}=1.22 \mathrm{~m}$, and $L_{z}=0.74 \mathrm{~m}$, is used in this study (Figure 1). There is a top vent on the ceiling and a bottom vent on the wall in this model. The areas of the top vent and the bottom vent are both $4.65 \times 10^{-2} \mathrm{~m}^{2}$. Model 1, Model 2, and Model 3 were chosen to investigate the leakage taking place at the floor of the space in the vertical direction. Model 4 and Model 5 were chosen to investigate the leakage taking place at the side wall of the space in the horizontal direction. The center coordinates of the leakage positions for Model 1-Model 5 are listed in Table 1. It is hypothesized that the pure hydrogen leaks into the space at a flow rate of $9.44 \times 10^{-4} \mathrm{~m}^{3} / \mathrm{s}$ ( 2 SCFM : standard cubic feet per minute) and the area of the inflow orifice is $4.65 \times 10^{-2} \mathrm{~m}^{2}$.

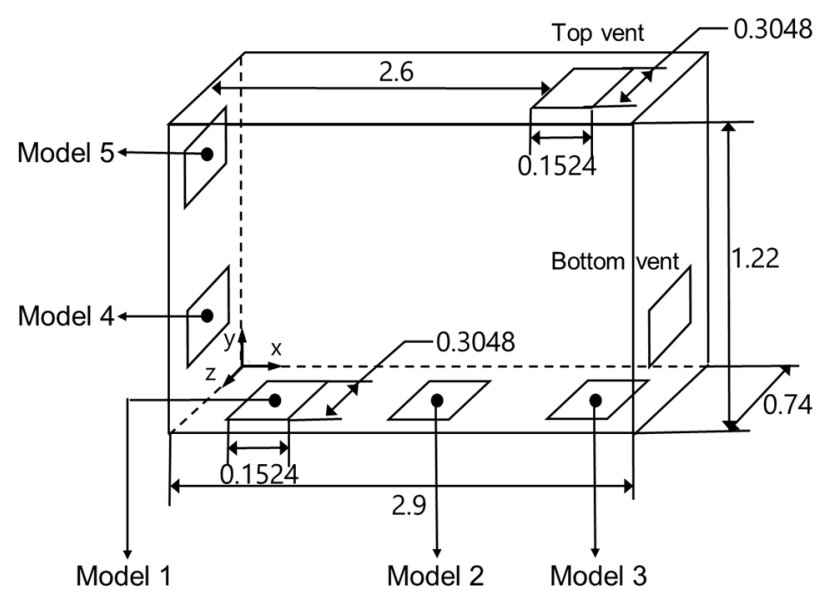

Figure 1. The schematic of the simplified model of a fuel cell bus (m).

Table 1. The center coordinates of the leakage positions.

\begin{tabular}{cccc}
\hline & $\mathbf{x}(\mathbf{m})$ & $\mathbf{y}(\mathbf{m})$ & $\mathbf{z}(\mathbf{m})$ \\
\hline Model 1 & 0.22 & 0.00 & 0.37 \\
Model 2 & 1.45 & 0.00 & 0.37 \\
Model 3 & 2.67 & 0.00 & 0.37 \\
Model 4 & 0.00 & 0.22 & 0.37 \\
Model 5 & 0.00 & 0.99 & 0.37 \\
\hline
\end{tabular}

\subsection{Numerical Methods}

The CFD (computational fluid dynamics) software Fluent was applied for the analysis in this study. Three main calculation models in Fluent, Species, Energy, and Viscous, were adopted to solve the continuity, momentum, volume fraction, and turbulent flow equations, respectively. 
A mixture of hydrogen and air was assumed as the incompressible gas, and the ideal gas law was selected as the density relationship. The operating pressure was set to 101,325 Pascals and Fick's law approximation was used for the species transport calculations. Moreover, the constant dilute approximation $\left(6.1 \times 10^{-5} \mathrm{~m}^{2} / \mathrm{s}\right)$ was selected for the mass diffusion coefficient. The following assumptions were made for the calculations:

1. The hydrogen released at a constant rate;

2. The phase change and chemical reaction were ignored during the leakage;

3. The wall was isothermal and adiabatic. In addition, there was no heat exchange between the hydrogen and air.

Reynolds-average Navier-Stokes (RANS) conservation equations were applied to solve mass, momentum, energy, and species,

$$
\begin{gathered}
\frac{\partial \bar{\rho}}{\partial t}+\frac{\partial\left(\bar{\rho} \tilde{u}_{j}\right)}{\partial x_{j}}=S_{\text {mass }}, \\
\frac{\partial \bar{\rho} \tilde{u}_{i}}{\partial t}+\frac{\partial\left(\bar{\rho} \tilde{u}_{j} \tilde{u}_{i}\right)}{\partial x_{j}}=-\frac{\partial(\bar{p})}{\partial x_{i}}+\frac{\partial}{\partial x_{j}}\left(\mu+\mu_{t}\right)\left(\frac{\partial\left(\tilde{u}_{i}\right)}{\partial x_{j}}+\frac{\partial\left(\tilde{u}_{j}\right)}{\partial x_{i}}-\frac{2}{3} \delta_{i j} \frac{\partial\left(\tilde{u}_{k}\right)}{\partial x_{k}}\right)+\bar{\rho} g_{i}, \\
\frac{\partial \tilde{E} \bar{\rho}}{\partial t}+\frac{\partial}{\partial x_{j}}\left(\tilde{u}_{j}(\tilde{E} \bar{\rho}+\bar{p})\right)=\frac{\partial}{\partial x_{j}}\left(\left(k+\frac{\mu_{t} c_{p}}{P r_{t}}\right) \frac{\partial(\tilde{T})}{\partial x_{j}}-\sum_{m} \tilde{h}_{m}\left(-\left(\rho D_{m}+\frac{\mu_{t}}{S c_{t}}\right) \frac{\partial \tilde{Y}_{m}}{\partial x_{j}}\right)+\tilde{u}_{i}\left(\mu+\mu_{t}\right)\left(\frac{\partial\left(\tilde{u}_{i}\right)}{\partial x_{j}}+\frac{\partial\left(\tilde{u}_{j}\right)}{\partial x_{i}}-\frac{2}{3} \delta_{i j} \frac{\partial\left(\tilde{u}_{k}\right)}{\partial x_{k}}\right)\right)+S_{E}, \\
\frac{\partial\left(\bar{\rho} \tilde{Y}_{m}\right)}{\partial t}+\frac{\partial}{\partial x_{j}}\left(\bar{\rho} \tilde{Y}_{m} \tilde{u}_{j}\right)=\frac{\partial}{\partial x_{i}}\left[\left(\bar{\rho} D_{m}+\frac{\mu_{t}}{S c_{t}}\right) \frac{\partial \tilde{Y}_{m}}{\partial x_{j}}\right]+S_{m}+R_{m},
\end{gathered}
$$

where $t$ is the time, $\rho$ is the density, $k$ represents turbulence kinetic energy, $\mu_{t}$ is the turbulent dynamic viscosity, $p$ is the pressure, $S_{\text {mass }}$ is the source term, which can be added by a user defined function (UDF), $u$ represents the velocity components, $E$ is the total energy, $\delta_{i j}$ is the Kronecker symbol, $C_{p}$ is the specific heat at constant pressure, $g_{i}$ is the gravitational acceleration, $S c_{t}$ and $P r_{t}$ are the turbulent Schmidt and energy turbulent Prandtl numbers, which are 0.7 and 0.85 , respectively, $Y_{m}$ is the mass fraction, $D_{m}$ is the molecular diffusivity of the species $\mathrm{m}, S_{E}$ is the source terms in the energy equation, $S_{m}$ and $R_{m}$ are the net production/consumption rate by species chemical reaction and the source term connected to any functions defined by the users for dispersed phase.

The RNG model was presented using renormalization group (RNG) methods, which renormalizes the RANS equations to explain the effects of smaller scales of motion. The equations of $k$ and $\varepsilon$ can be written as

$$
\begin{gathered}
\frac{\partial(\rho k)}{\partial t}+\frac{\partial\left(\rho \mathrm{ku}_{i}\right)}{\partial x_{i}}=\frac{\partial}{\partial x_{j}}\left[\alpha_{k} \mu_{e f f} \frac{\partial k}{\partial x_{j}}\right]+G_{K}-\rho \varepsilon \\
\frac{\partial(\rho \varepsilon)}{\partial t}+\frac{\partial\left(\rho \varepsilon u_{i}\right)}{\partial x_{i}}=\frac{\partial}{\partial x_{j}}\left[\alpha_{\varepsilon} \mu_{e f f} \frac{\partial \varepsilon}{\partial x_{j}}\right]+C_{1 \varepsilon} \frac{\varepsilon}{k} G_{K}-C_{2 \varepsilon}^{*} \rho \frac{\varepsilon^{2}}{k} \\
\mu_{e f f}=\mu+\mu_{t^{\prime}} \\
\mu_{t}=\rho C_{\mu} \frac{k^{2}}{\varepsilon}
\end{gathered}
$$

where $C_{\mu}=0.0845 ; \alpha_{k}=\alpha_{\varepsilon}=1.39$,

$$
C_{2 \varepsilon}^{*}=C_{2 \varepsilon}-\frac{\eta\left(1-\eta / \eta_{0}\right)}{1+\beta \eta^{3}}
$$


where $C_{1 \varepsilon}=1.42 ; C_{2 \varepsilon}=1.68 ; \beta=0.012$

$$
\begin{gathered}
\eta=\left(2 E_{i j} \cdot E_{i j}\right)^{1 / 2} \frac{k}{\varepsilon}, \\
E_{i j}=\frac{1}{2}\left(\frac{\partial u_{i}}{\partial x_{j}}+\frac{\partial u_{j}}{\partial x_{i}}\right) \eta_{0}=4.377,
\end{gathered}
$$

where $G_{K}$ is the production of turbulent kinetic energy generated by the average velocity gradient, $C_{1 \varepsilon}$ and $C_{2 \varepsilon}$ are empirical constants, and $\alpha_{k}$ and $\alpha_{\varepsilon}$ are separate corresponding Prandtl values for $k$ and $\varepsilon$.

In order to enhance the efficiency of the calculations, the calculation domain was meshed onto non-homogeneous hexahedrons. Before the face sizing was chosen, a mesh convergence test was performed. To test the convergence, the mole fraction of hydrogen for Model 1 was compared at four points S1, S2, S3, and S4, whose coordinates were $(0.152 \mathrm{~m}$, $0.152 \mathrm{~m}$, and $0.596 \mathrm{~m}),(0.152 \mathrm{~m}, 1.009 \mathrm{~m}$, and $0.219 \mathrm{~m}),(2.676 \mathrm{~m}, 1.009 \mathrm{~m}$, and $0.596 \mathrm{~m})$, and $(2.676 \mathrm{~m}, 0.152 \mathrm{~m}$, and $0.219 \mathrm{~m})$, respectively. The three different mesh face sizings were $0.018 \mathrm{~m}, 0.024 \mathrm{~m}$, and $0.030 \mathrm{~m}$, and the corresponding number of elements were 113,812 , 230,972 , and 369,015 . The mole fractions of hydrogen deviation from the results of the refined mesh (number of elements is 369,015 ) were all less than $3 \%$, as shown in Table 2. Therefore, a face sizing of $0.03 \mathrm{~m}$ was chosen for investigation.

\begin{tabular}{|c|c|c|c|c|c|c|c|c|c|}
\hline \multirow{2}{*}{$\begin{array}{c}\text { No. of } \\
\text { Elements }\end{array}$} & \multirow{2}{*}{$\begin{array}{c}\text { Mesh } \\
\text { Size (m) }\end{array}$} & \multicolumn{2}{|c|}{ S1 } & \multicolumn{2}{|c|}{ S2 } & \multicolumn{2}{|c|}{ S3 } & \multicolumn{2}{|c|}{ S4 } \\
\hline & & $\begin{array}{c}\text { Mole } \\
\text { Fraction }\end{array}$ & Deviation & $\begin{array}{c}\text { Mole } \\
\text { Fraction }\end{array}$ & Deviation & $\begin{array}{c}\text { Mole } \\
\text { Fraction }\end{array}$ & Deviation & $\begin{array}{c}\text { Mole } \\
\text { Fraction }\end{array}$ & Deviation \\
\hline 113,812 & 0.030 & 3.82 & 2.35 & 5.18 & 0.97 & 5.11 & 0.19 & 3.35 & 2.98 \\
\hline 230,972 & 0.024 & 3.81 & 2.62 & 5.20 & 1.36 & 5.05 & 1.38 & 3.41 & 1.17 \\
\hline 369,015 & 0.018 & 3.91 & - & 5.13 & - & 5.12 & - & 3.45 & - \\
\hline
\end{tabular}

Table 2. Mesh convergence study.

The boundary conditions were set as below. The inlet boundary was defined as the velocity inlet. The direction of the velocity was defined normal to the inlet surface and the speed of the hydrogen through the leakage was kept constant at $0.02 \mathrm{~m} / \mathrm{s}$. The vents were defined as zero-gauge pressure outlets. The intensity of $1 \%$ and the hydraulic diameter of $0.198 \mathrm{~m}$ were selected as the specification method for the turbulence. The SIMPLE (semi-implicit method for pressure-linked equations) was used in all the simulations, along with second-order spatial discretization. The transient flow mode was used, and the convergence criteria were set to $10^{-4}$.

\section{Results and Discussions}

\subsection{Vertical Release Through the Leakages on the Floor \\ 3.1.1. Iso-Surface of $4 \%$ Mole Fraction}

In terms of the dispersion of hydrogen, the diffusion progress can be divided into two phases.

1. The first phase: the hydrogen rises from the leakage position to the ceiling.

2. The second phase: the hydrogen extends along the ceiling after getting to the ceiling.

The dispersion of hydrogen for Model 1, Model 2, and Model 3 can be seen in Figure 2. Hydrogen can be combusted at atmospheric pressure at concentrations from $4 \%$ to $74 \%$ by volume. The volume fraction of the substance is equal to the mole fraction for ideal gas mixture. Based on the assumptions for ideal gas, the mole fraction was used to investigate the diffusion progress of hydrogen in this study. The iso-surfaces show the extent of the flammable atmosphere ( $4 \%$ mole fraction). The time required for the iso-surface of $4 \%$ mole fraction to rise to the ceiling for Model 1, Model 2, and Model 3 was 250 s, 230 s, and 400 s, 
respectively, and the concentration envelope was of a cylindrical shape. It is evident that the time for Model 3 was the longest, while it was the shortest for Model 2.
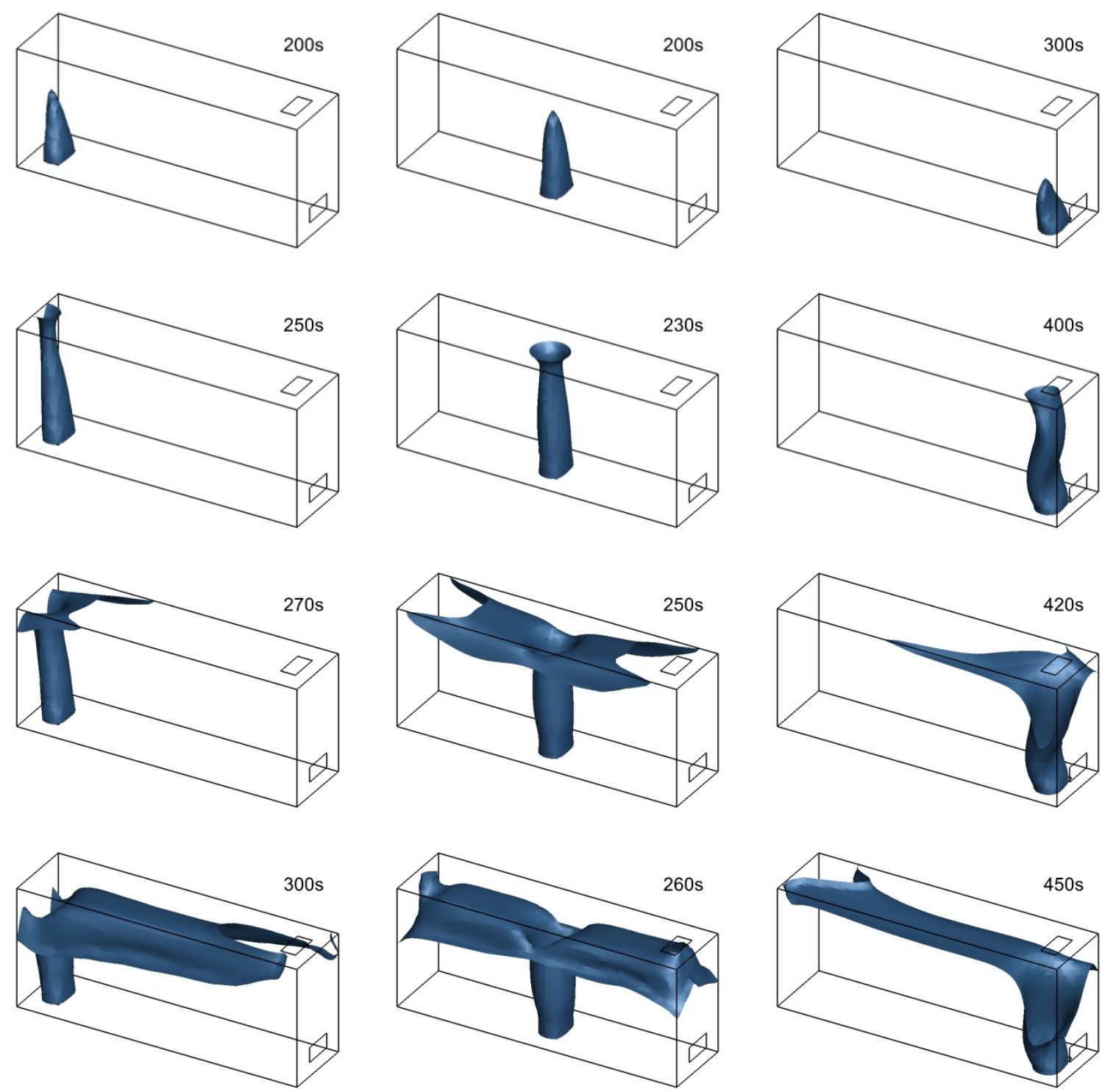

Figure 2. Iso-surface of 4\% hydrogen mole fraction for Model 1 (left), Model 2 (middle), and Model 3 (right).

The velocity vectors in the median plane $z=0.37$ of the envelope of the iso-surfaces of $4 \%$ mole fraction rising to the ceiling is illustrated in Figure 3. The distance between the leak position and the bottom vent in Model 2 is farther than that in Model 3, but closer than that in Model 1. From the results of the velocity vector shown in the circulation zone between the leakage position and the ceiling, the fastest vertical speed (approximately $0.33 \mathrm{~m} / \mathrm{s}$ ) was in Model 2. It contributed to the shortest time spent by Model 2 during the first phase. In the case of Model 3, the top vent is above the leakage position, and a large amount of hydrogen is discharged. Therefore, it takes a longer time for the iso-surface of $4 \%$ mole fraction to diffuse to the ceiling (Figure 3). 


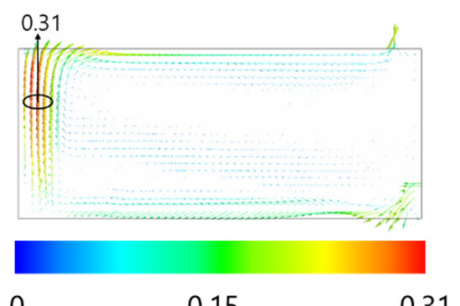

0

0.15

0.31

$t=250 \mathrm{~s}$

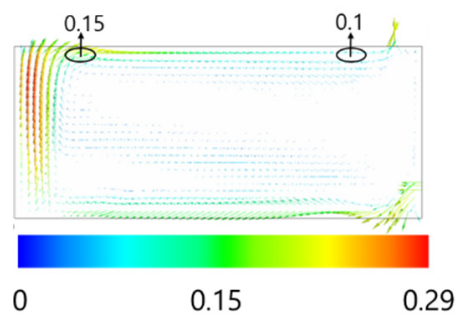

$t=300 s$

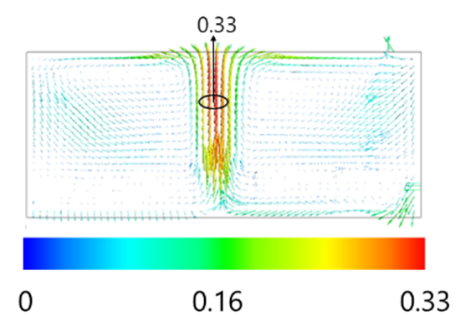

$t=230 s$

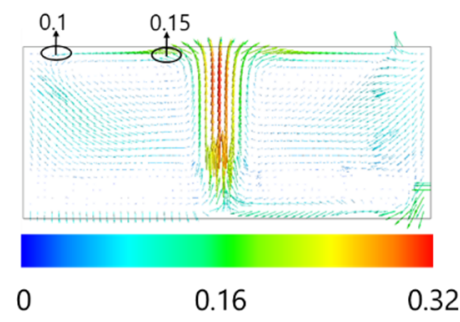

$t=260 s$

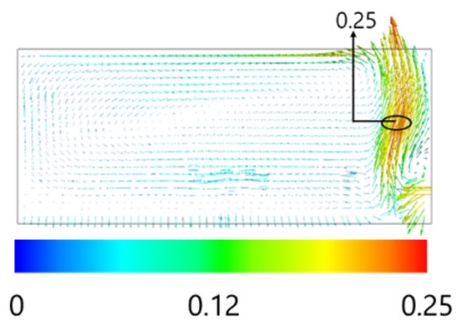

$\mathrm{t}=400 \mathrm{~s}$

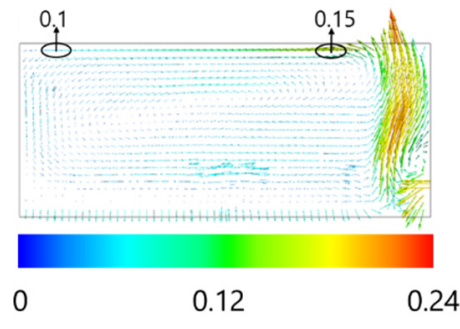

$\mathrm{t}=450 \mathrm{~s}$

Figure 3. Velocity vectors for Model 1 (left), Model 2 (middle), and Model 3 (right) whilst the envelope of $4 \%$ mole fraction of hydrogen was rising to the ceiling (up) and filling the whole ceiling (down) (m/s).

After getting to the ceiling, the envelope of iso-surfaces of $4 \%$ mole fraction extends along the ceiling and its shape is like a mushroom. The time required for the iso-surface of $4 \%$ mole fraction to extend along the ceiling for Model 1, Model 2, and Model 3 was $50 \mathrm{~s}, 30 \mathrm{~s}$, and $50 \mathrm{~s}$, respectively. It was found that the time required for Model 2 was about half of that for Model 1 and Model 3. This can be seen from the velocity vectors of the median plane $\mathrm{z}=0.37$ for the envelope of the iso-surfaces of $4 \%$ mole fraction diffusing horizontally along the ceiling (Figure 1). In the case of Model 1, Model 2, and Model 3, the horizontal diffusion velocity at the start and the end of the ceiling was about $0.15 \mathrm{~m} / \mathrm{s}$ and $0.1 \mathrm{~m} / \mathrm{s}$, respectively, and the leakage position had little effect on the horizontal diffusion velocity of the iso-surface of $4 \%$ mole fraction at the ceiling.

\subsubsection{Iso-Surface of $1 \%$ Mole Fraction}

Standards ISO/DIS 19880-1, NFPA 2, and IEC (60079-10) require that the ventilation rate should ensure a maximum hydrogen mole fraction at $1 \%$ for enclosures and buildings containing hydrogen equipment. Therefore, the iso-surface of $1 \%$ mole fraction should be investigated to provide guidance for the layout of hydrogen sensors.

Iso-surfaces of 1\% mole fraction rising to the ceiling for Model 1, Model 2, and Model 3 are illustrated in Figure 4. During the first phase, the time required for Model 1, Model 2, and Model 3 to rise to the ceiling was $10 \mathrm{~s}, 13 \mathrm{~s}$, and $10 \mathrm{~s}$, respectively, and the concentration envelope was a cylinder shape. It is evident that the time for Model 2 was the longest. 

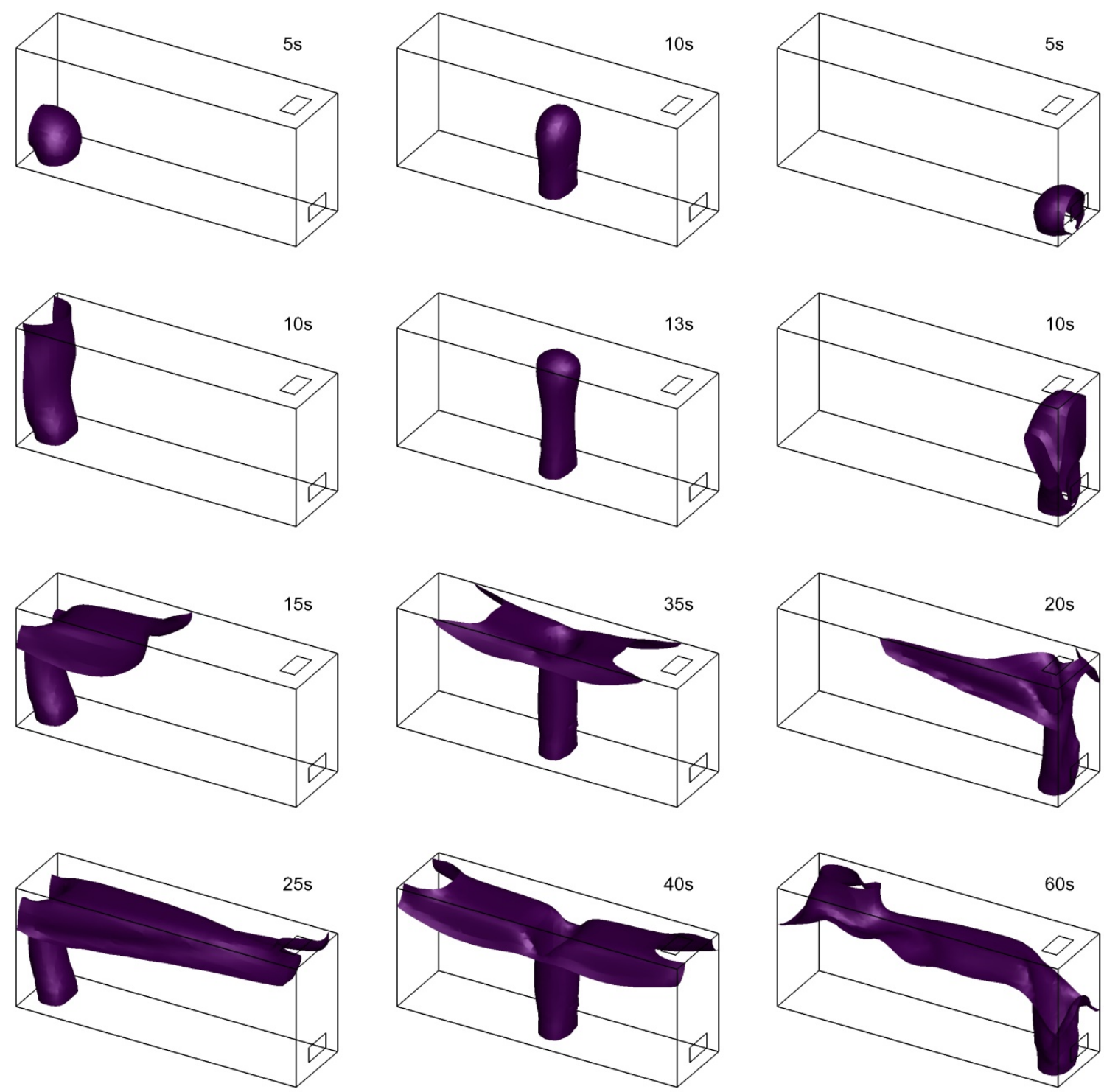

Figure 4. Iso-surface of $1 \%$ hydrogen mole fraction for Model 1 (left), Model 2 (middle), and Model 3 (right).

The velocity vectors in the median $\mathrm{z}=0.37$ plane while the envelope of the iso-surfaces of $1 \%$ mole fraction was rising to the ceiling and extending horizontally to the end of the ceiling is illustrated in Figure 5. It can be seen from the figure that it takes almost the same amount of time for Model 1, Model 2, and Model 3 during the first diffusion phase.

Like the aforementioned iso-surface of $4 \%$ mole fraction, the envelope of iso-surfaces of $1 \%$ mole fraction also extended along the ceiling during the second phase after getting to the ceiling. The time required for Model 1, Model 2, and Model 3 in the second phase was $15 \mathrm{~s}, 27 \mathrm{~s}$, and $50 \mathrm{~s}$, respectively. It was the shortest for Model 1, which might be due to the distance between the leakage position and the bottom vent being longer than those for Model 2 and Model 3. The result indicates that the time required for the iso-surface of $1 \%$ mole fraction to diffuse horizontally along the ceiling decreases with the increase of the distance between the leakage position and the bottom vent, and hydrogen tends to accumulate. 


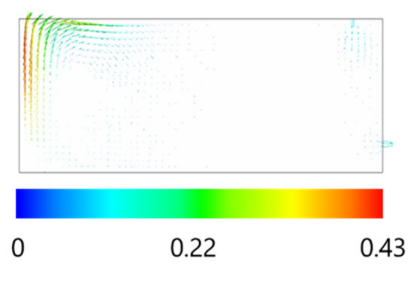

$\mathrm{t}=10 \mathrm{~s}$

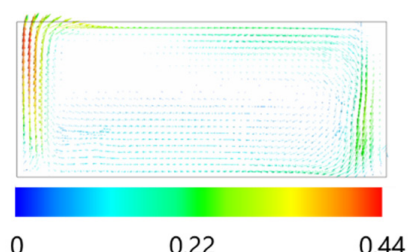

$t=25 s$

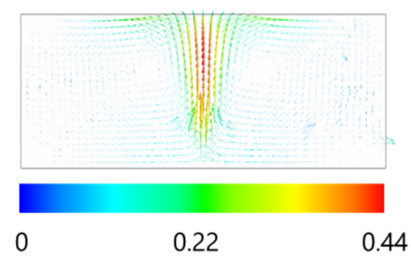

$t=13 s$

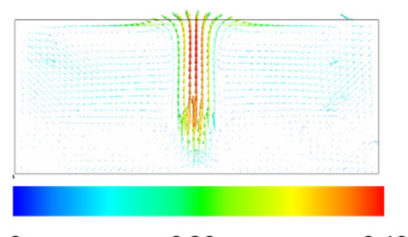

0.20

$\mathrm{t}=40 \mathrm{~s}$
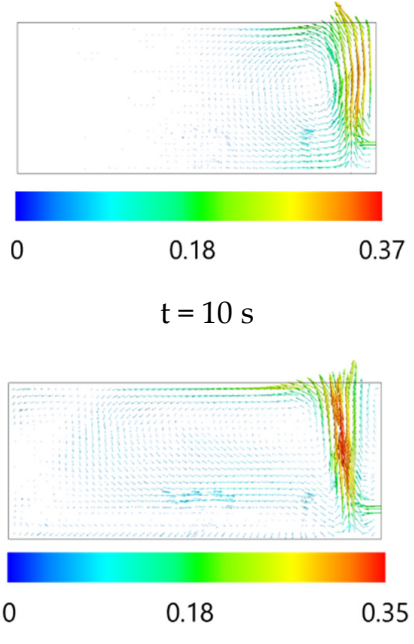

$t=60 s$

Figure 5. Velocity vectors for Model 1 (left), Model 2 (middle), and Model 3 (right) whilst the envelope of 1\% mole fraction of hydrogen was rising to the ceiling (up) and filling the whole ceiling (down) (m/s).

\subsection{Horizontal Release through the Leakages on the Wall}

\subsubsection{Iso-Surface of $4 \%$ Mole Fraction}

The iso-surface of $4 \%$ mole fraction of hydrogen for Model 4 and Model 5 can be seen in Figure 6. Like Model 1, Model 2, and Model 3, the dispersion process for Model 4 and Model 5 consisted of two phases. In the first phase, the time required for the iso-surface of $4 \%$ mole fraction for Model 4 and Model 5 to rise to the ceiling was $100 \mathrm{~s}$ and $5 \mathrm{~s}$, respectively, and the shape of the concentration envelope was similar to a rectangle. The distance between the leakage position and the ceiling for Model 4 was greater than for Model 5, and thus took a longer time for the dispersion.
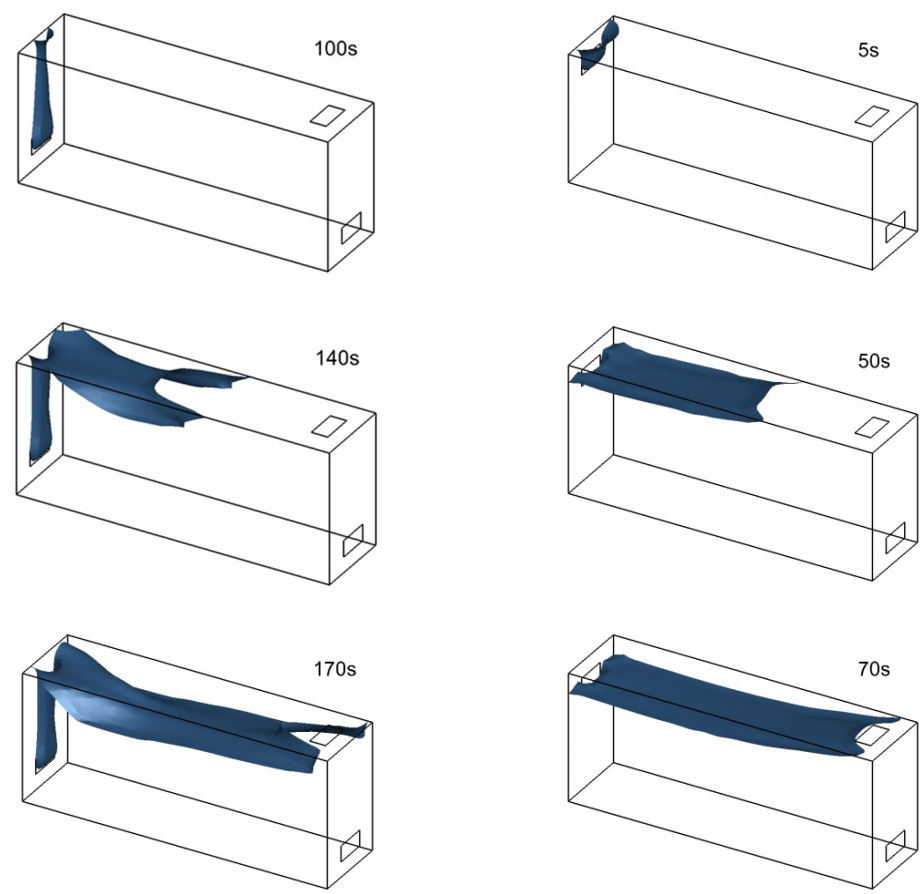

Figure 6. Iso-surface of $4 \%$ hydrogen mole fraction for Model 4 (left) and Model 5 (right). 
In the second phase, the envelope of iso-surfaces of $4 \%$ mole fraction extended horizontally along the ceiling. The amount of time required for the envelope of iso-surfaces of $4 \%$ mole fraction in the whole diffusion process, including two phases, rising to the ceiling and extending along the ceiling, was $170 \mathrm{~s}$ and $70 \mathrm{~s}$, respectively. Therefore, the time required for both Model 4 and Model 5 in the second phase was about $70 \mathrm{~s}$. It is evident that the time for Model 4 and Model 5 was almost equal. The velocity vectors in the $\mathrm{z}=0.37$ plane for the envelope of iso-surfaces of $4 \%$ mole fraction rising to the ceiling and diffusing horizontally is illustrated in Figure 7 . The horizontal diffusion velocity along the ceiling was about $0.15 \mathrm{~m} / \mathrm{s}$ for Model 4 and Model 5, respectively. Therefore, the time for diffusing horizontally along the ceiling for Model 4 and Model 5 was almost equal. The height of the leakage taking place on the wall had little effect on the horizontal diffusion velocity of the iso-surface of $4 \%$ mole fraction at the ceiling.
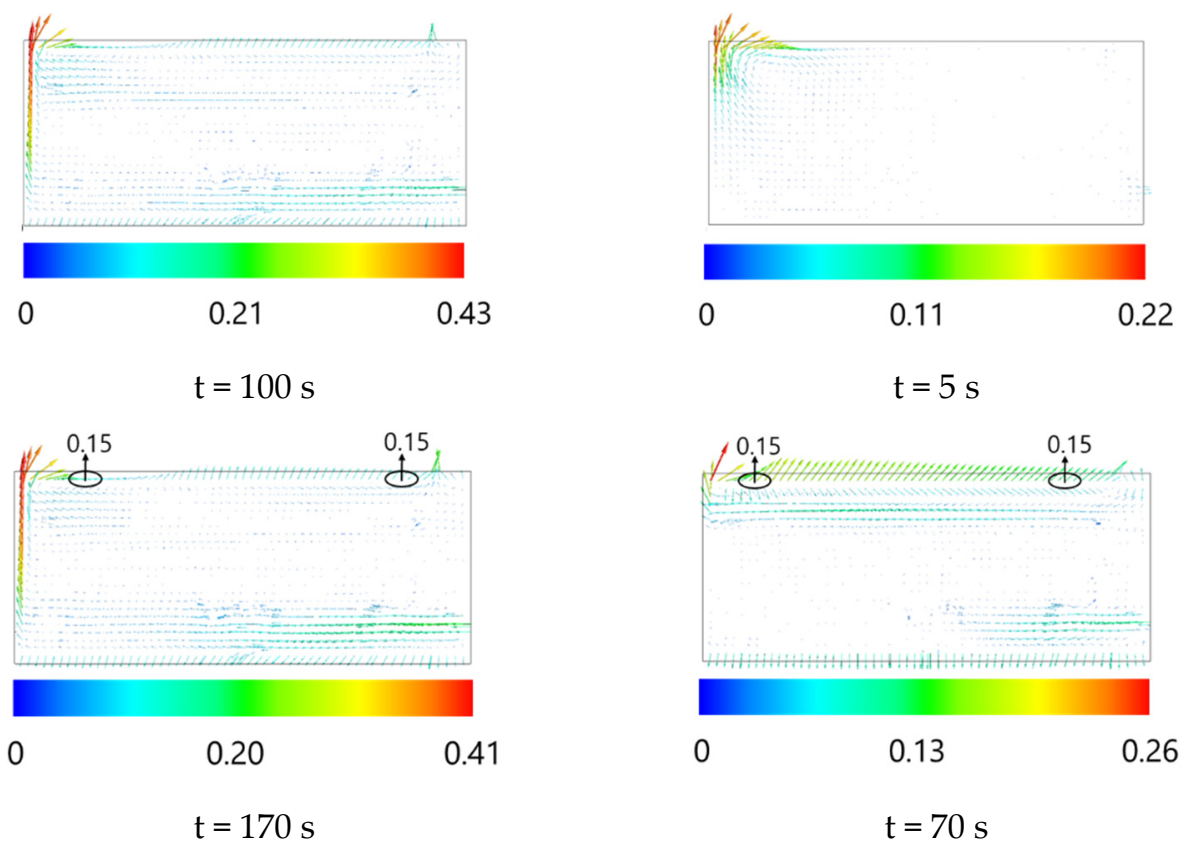

Figure 7. Velocity vectors for Model 4 (left) and Model 5 (right) whilst the envelope of $4 \%$ mole fraction of hydrogen was rising to the ceiling (up) and filling the whole ceiling (down) $(\mathrm{m} / \mathrm{s})$.

\subsubsection{Iso-Surface of $1 \%$ Mole Fraction}

The dispersion of hydrogen for Model 4 and Model 5 can be seen in Figure 8. In the first phase, the time required for the iso-surface of $1 \%$ mole fraction for Model 4 and Model 5 to rise to the ceiling was $6 \mathrm{~s}$ and $5 \mathrm{~s}$, respectively, and the shape of the concentration envelope was similar to a rectangle.

In the second phase, the envelope of iso-surfaces of $1 \%$ mole fraction extended horizontally along the ceiling. The amount of time required for the envelope of iso-surfaces of $1 \%$ mole fraction for the whole process for Model 4 and Model 5 was $20 \mathrm{~s}$, equally. Therefore, the time required for the two models during the second phase was about $15 \mathrm{~s}$ in total.

The velocity vectors in the $\mathrm{z}=0.37$ plane for the envelope of iso-surfaces of $1 \%$ mole fraction rising to the ceiling and diffusing horizontally is illustrated in Figure 9. The horizontal diffusion velocity at the ceiling was about $0.2 \mathrm{~m} / \mathrm{s}$ for Model 4 and Model 5 . Therefore, the amount of time for diffusing horizontally along the ceiling for these two models was almost equal. The height of leakage taking place at the wall had little effect on the horizontal diffusion velocity of the iso-surface of $1 \%$ mole fraction along the ceiling. 

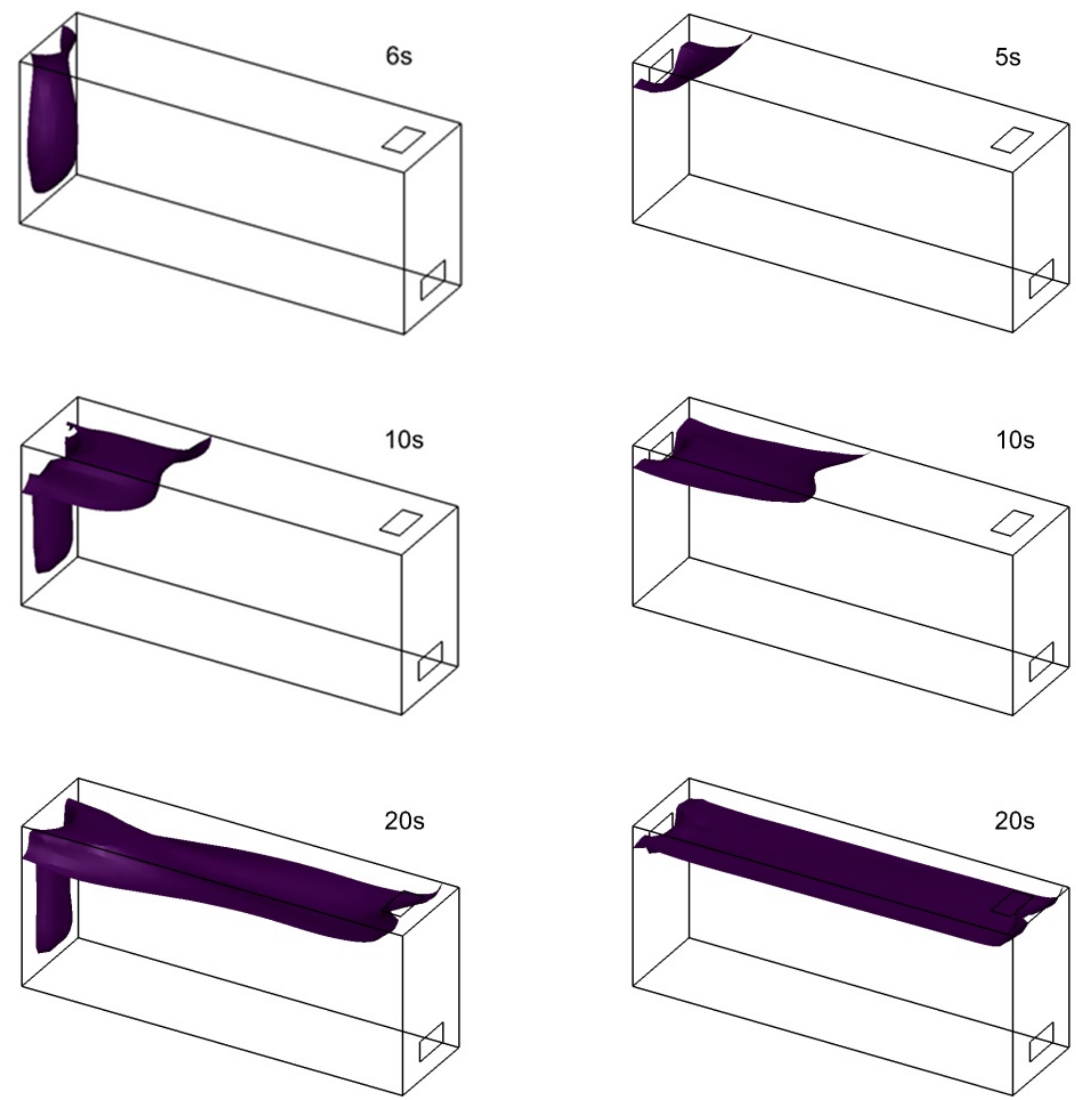

Figure 8. Iso-surface of $1 \%$ hydrogen mole fraction for Model 4 (left) and Model 5 (right).
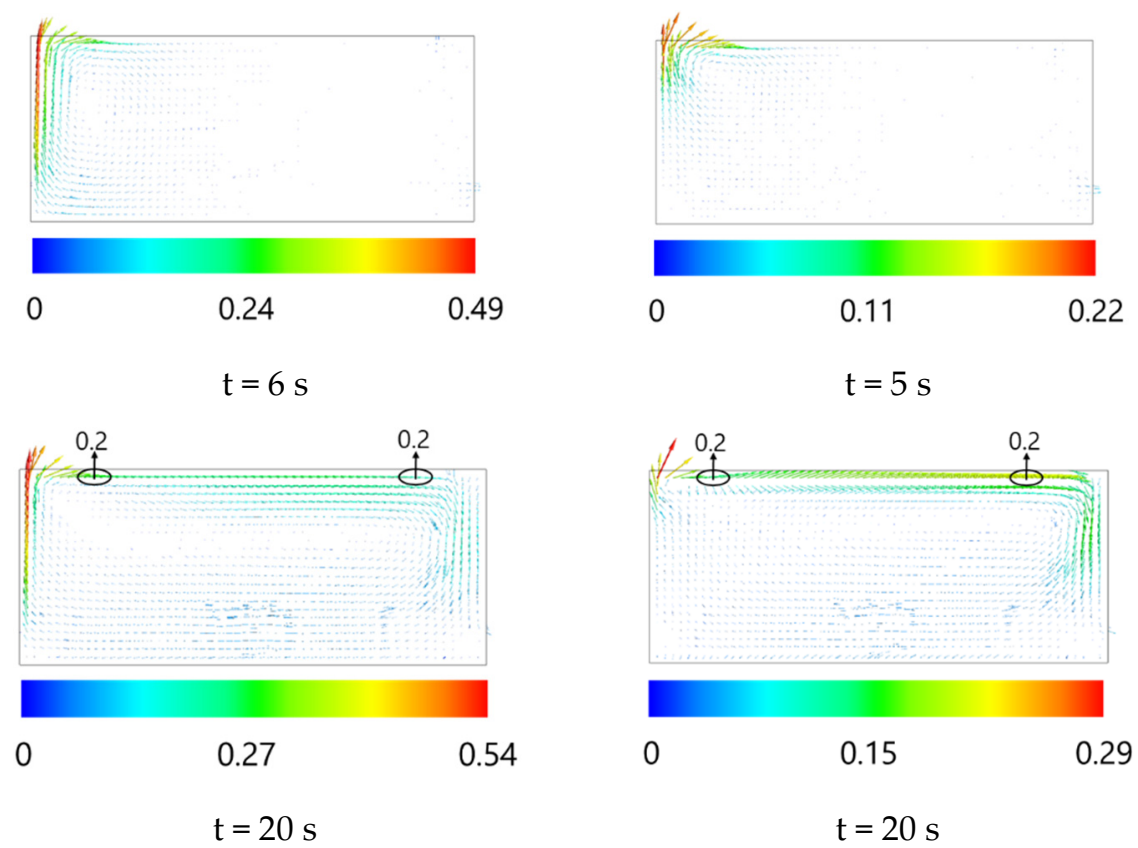

Figure 9. Velocity vectors for Model 4 (left) and Model 5 (right) whilst the envelope of $1 \%$ mole fraction of hydrogen was rising to the ceiling (up) and filling the whole ceiling (down) (m/s). 


\subsection{Effect of the Leakage Direction}

\subsubsection{Stratification}

In order to compare the hydrogen concentration for Model 1-Model 5, the $x=1$ plane in the space was selected to study the contour at the time when the envelopes of $4 \%$ and $1 \%$ mole fraction of hydrogen grew to fill the whole ceiling. As is evident from Figure 10, hydrogen gradually accumulated downward from the ceiling and stratification happened for Model 1-Model 5. The area occupied by the hydrogen concentration below $0.5 \%$ for Model4 and Model 5 was larger than that for Model 1, Model 2, and Model 3. The Merton number was used to distinguish the homogeneous and stratification. The definition of the Merton number $M$ is as follows:

$$
\begin{gathered}
M=\frac{l_{s}}{z}, \\
l_{s}=\frac{M_{0}^{3 / 4}}{F_{0}^{1 / 2}}=\frac{0.96 \cdot u_{0} \cdot \sqrt{D}}{\sqrt{\frac{g \cdot\left(\rho_{\text {air }}-\rho_{\mathrm{H}_{2}}\right)}{\rho_{\text {air }}}}},
\end{gathered}
$$

where $u_{0}$ is the exit velocity, $\mathrm{m} \cdot \mathrm{s}^{-1} ; D$ is the diameter of the leak, $\mathrm{m} ; g$ is the acceleration of gravity, $\mathrm{m} \cdot \mathrm{s}^{-2} ; \rho_{\text {air }}$ is the density of air, $\mathrm{kg} \cdot \mathrm{m}^{-3} ; \rho_{H 2}$ is the density of hydrogen, $\mathrm{kg} \cdot \mathrm{m}^{-3}$; and $z$ is the distance between the leakage position and the ceiling, $\mathrm{m}$.
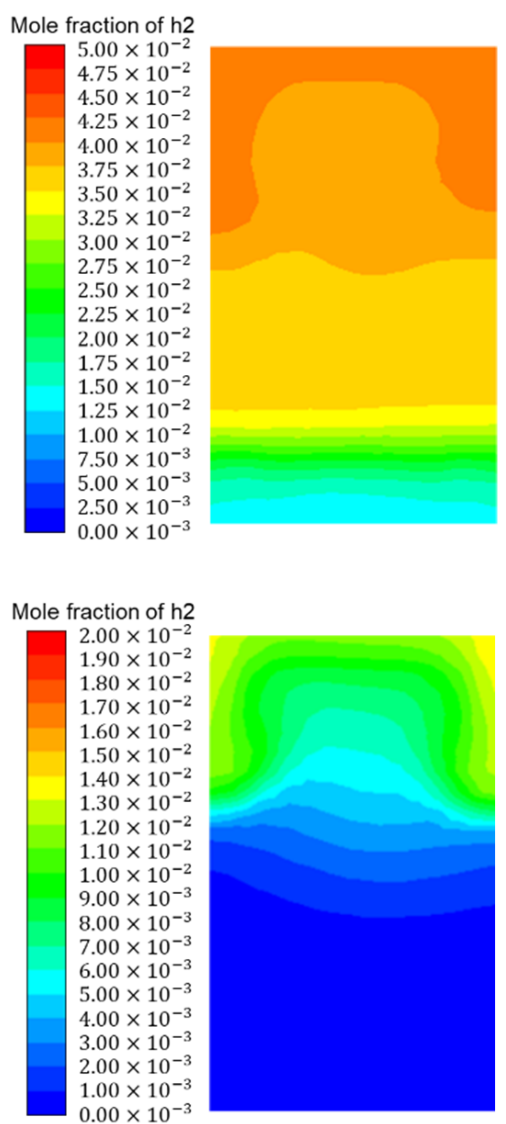

Model 1
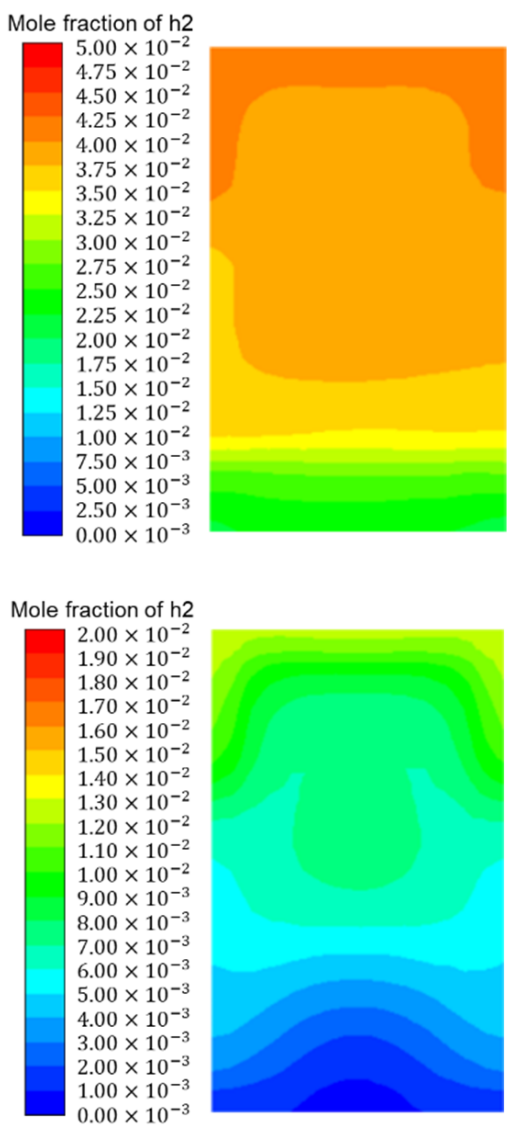

Model 2
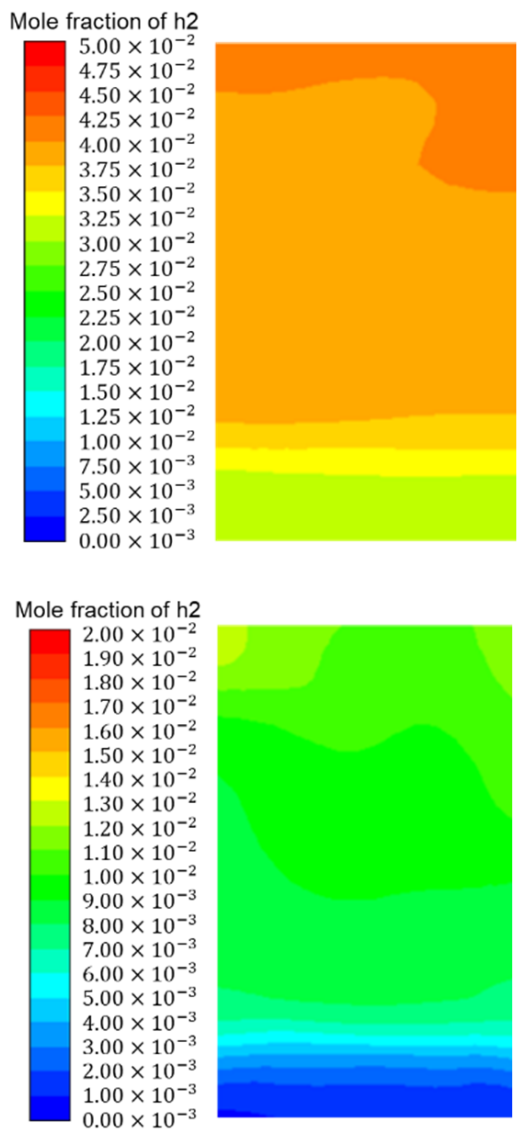

Model 3

Figure 10. Cont. 

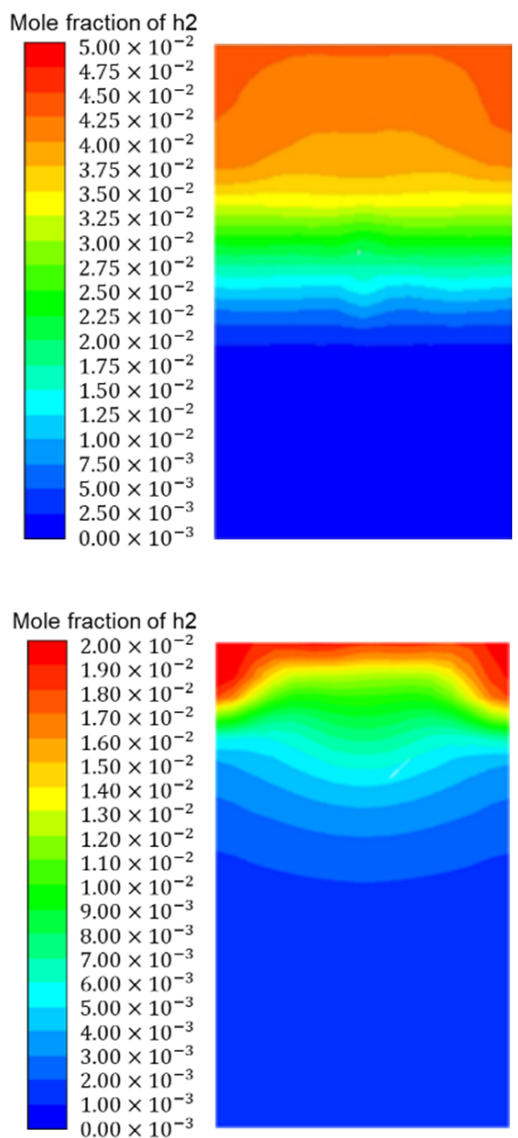

Model 4
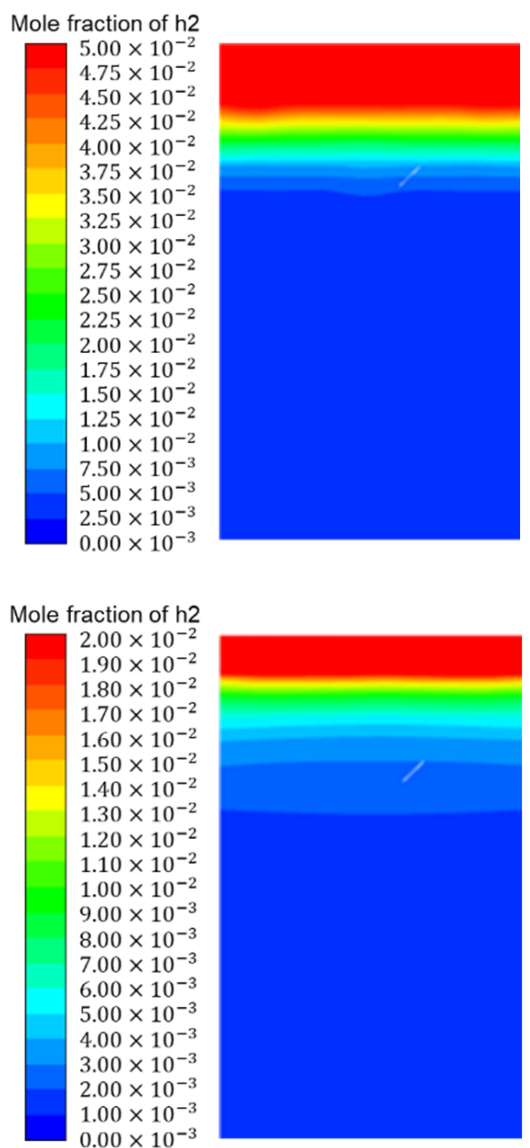

Model 5

Figure 10. Contours of mole concentration of hydrogen for Model 1-Model 5 after the envelope of $4 \%$ mole fraction (up) and 1\% mole fraction (down) of hydrogen filling the whole ceiling.

For $M<1$, there is a stratification of the concentration of hydrogen, whereas for $M \gg 1$, homogenization is observed. The Merton number of Model 1, Model 2, and Model 3 was about 0.00236 , equally. The number of Model 4 and Model 5 was 0.00282 and 0.013, respectively. The Merton number in all cases was less than 1 , so that stratification happened.

The stratification was found to happen in a large velocity range, and tended to occur in the space with the leakage taking place near the ceiling [42]. As is evident from Figure 10, the stratification of both $4 \%$ and $1 \%$ mole fraction of hydrogen for Model 5 was more obvious than the other models due to the leakage position closer to the ceiling. Hajij et al. [26] also found stratification in a prismatic cavity.

\subsubsection{Diffusion Velocity}

In order to compare the influence of leak direction on the diffusion velocity, the amount of time for iso-surfaces of $4 \%$ and $1 \%$ mole fraction in each stage of diffusion for Model 1-Model 5 is listed in Table 3. In the first phase, the time required for $4 \%$ mole fraction hydrogen diffusion in Model 4 and Model 5 was $100 \mathrm{~s}$ and $5 \mathrm{~s}$, respectively, which was a shorter time than for Model 1, Model 2, and Model 3. The time required for the whole process of $1 \%$ mole fraction hydrogen diffusion for Model 4 and Model 5 was $20 \mathrm{~s}$, which was shorter than for Model 1, Model 2, and Model 3. From the results of the velocity vectors shown in Figures 3 and 7, it can be seen that the diffusion velocity at the ceiling was about $0.15 \mathrm{~m} / \mathrm{s}$ for Model 1-Model 5 . The leak direction had little effect on the horizontal diffusion velocity near the ceiling, but it significantly affected the velocity rising to the ceiling. 
Table 3. The time for iso-surfaces of $4 \%$ and $1 \%$ mole fraction of the hydrogen diffusion process for Model 1-Model 5.

\begin{tabular}{ccccc}
\hline & \multicolumn{2}{c}{ Iso-Surface of $\mathbf{4} \%$ Mole Fraction } & \multicolumn{2}{c}{ Iso-Surface of $\mathbf{1 \%}$ Mole Fraction } \\
\hline & Phase $\mathbf{1}$ & Phase $\mathbf{2}$ & Phase $\mathbf{~}$ & Phase 2 \\
\hline Model 1 & $250 \mathrm{~s}$ & $50 \mathrm{~s}$ & $10 \mathrm{~s}$ & $15 \mathrm{~s}$ \\
Model 2 & $230 \mathrm{~s}$ & $30 \mathrm{~s}$ & $13 \mathrm{~s}$ & $27 \mathrm{~s}$ \\
Model 3 & $400 \mathrm{~s}$ & $50 \mathrm{~s}$ & $10 \mathrm{~s}$ & $50 \mathrm{~s}$ \\
Model 4 & $100 \mathrm{~s}$ & $70 \mathrm{~s}$ & $6 \mathrm{~s}$ & $14 \mathrm{~s}$ \\
Model 5 & $5 \mathrm{~s}$ & $65 \mathrm{~s}$ & $5 \mathrm{~s}$ & $15 \mathrm{~s}$ \\
\hline
\end{tabular}

\section{Conclusions}

For the leakage taking place on the floor in the vertical direction, hydrogen was more likely to accumulate, as the leakage position was farther away from the wall with the bottom vent. For the leakage taking place on the wall in the horizontal direction, the height of the leakage had little effect on the horizontal diffusion velocity of the hydrogen at the ceiling.

The leakage in the present study involved two phases: the hydrogen rising, and then extending to the whole ceiling of the space. Compared to the leakage in the vertical direction, the process of leakage in the horizontal direction took less time.

The leakage direction had little effect on the horizontal diffusion velocity at the ceiling. Stratification occurred for the models set up in the present study whenever the envelope of $1 \%$ mole fraction or $4 \%$ mole fraction of hydrogen was extended to the whole ceiling. Compared with other models, the stratification in Model 5, where the leakage position was closer to the ceiling, was more obvious.

Author Contributions: Conceptualization, X.Z. and Y.L.; methodology, X.Z., Y.L., Y.M. and K.L.; software, Q.W.; validation, X.Z., Q.W. and X.H.; formal analysis, X.Z. and Q.W.; investigation, X.Z., X.H. and Q.W.; resources, X.Z., L.Z. and Y.M.; data curation, Q.W. and Y.L.; writing-original draft preparation, X.Z. and Q.W.; writing—review and editing, Y.L.; visualization, L.Z. and K.L.; supervision, Y.L.; project administration, Y.L.; funding acquisition, Y.L. All authors have read and agreed to the published version of the manuscript.

Funding: This research was funded by National Key Research and Development Program of China, grant number 2018YFE0105300, and National Natural Science Foundation of China, grant number $51605010,51975011$.

Institutional Review Board Statement: Not applicable.

Informed Consent Statement: Not applicable.

Data Availability Statement: The data presented in this study are available on request from the corresponding author.

Conflicts of Interest: The authors declare no conflict of interest.

\section{References}

1. Piraino, F.; Genovese, M.; Fragiacomo, P. Towards a new mobility concept for regional trains and hydrogen infrastructure. Energy Convers. Manag. 2020, 228, 113650. [CrossRef]

2. Petronilla, F.; Matteo, G. Technical-economic analysis of a hydrogen production facility for power-to-gas and hydrogen mobility under different renewable sources in Southern Italy. Energy Convers. Manag. 2020, 223, 113332.

3. Veziroğlu, T.N.; Şahi, N.S. 21st Century's energy: Hydrogen energy system. Energy Convers. Manag. 2008, 49, $1820-1831$. [CrossRef]

4. Piera, M.; Martínez-Val, J.M.; José Montes, M. Safety issues of nuclear production of hydrogen. Energy Convers. Manag. 2006, 47, 2732-2739. [CrossRef]

5. Abdo, P.; Huynh, B.P.; Irga, P.J.; Torpy, F.R. Evaluation of air flow through an active green wall biofilter. Urban For. Urban Green. 2019, 41, 75-84. [CrossRef]

6. Abdo, P.; Huynh, B.P.; Irga, P.J.; Torpy, F.R. Distribution of air flow through a green wall module. In Proceedings of the ASME 2017 Fluids Engineering Division Summer Meeting, Waikoloa, HI, USA, 30 July 2017. 
7. Swain, M.R.; Grilliot, E.S.; Swain, M.N. Risks incurrded by hydrogen escaping from containers and conduits. Hydrog. Program Rev. 1998, 2, 113-121.

8. Matsuura, K.; Kanayama, H.; Tsukikawa, H.; Inoue, M. Numerical simulation of leaking hydrogen dispersion behavior in a partially open space. Int. J. Hydrog. Energy 2008, 33, 240-247. [CrossRef]

9. Barley, C.D.; Gawlik, K. Buoyancy-driven ventilation of hydrogen from buildings: Laboratory test and model validation. Int. J. Hydrog. Energy 2009, 34, 5592-5603. [CrossRef]

10. Bernard-Michel, G.; Houssin-Agbomson, D. Comparison of helium and hydrogen releases in $1 \mathrm{~m} 3$ and $2 \mathrm{~m} 3$ two vents enclosures: Concentration measurements at different flow rates and for two diameters of injection nozzle. Int. J. Hydrog. Energy 2017, 42, 7542-7550. [CrossRef]

11. Pitts, W.M.; Yang, J.C.; Blais, M.; Joyce, A. Dispersion and burning behavior of hydrogen released in a full-scale residential garage in the presence and absence of conventional automobiles. Int. J. Hydrog. Energy 2012, 37, 17457-17469. [CrossRef]

12. Merilo, E.G.; Groethe, M.A.; Colton, J.D.; Chiba, S. Experimental study of hydrogen release accidents in a vehicle garage. Int. J. Hydrog. Energy 2011, 36, 2436-2444. [CrossRef]

13. Swain, M.R.; Grilliot, E.S.; Swain, M.N. Experimental verification of a hydrogen risk assessment method. Chem. Health Saf. 1999, 6, 28-32. [CrossRef]

14. Pitts, W.M.; Yang, J.C.; Fernandez, M.G. Helium dispersion following release in a 1/4-scale two-car residential garage. Int. J. Hydrog. Energy 2012, 37, 5286-5298. [CrossRef]

15. Punetha, M.; Choudhary, A.; Khandekar, S. Stratification and mixing dynamics of helium in an air filled confined enclosure. Int. J. Hydrog. Energy 2018, 43, 19792-19809. [CrossRef]

16. Wang, Y.; Chen, Y.; Zhao, H.; Xiong, Y. Study on the influence of barriers in the diffusion process of liquid hydrogen leakage. IOP Conf. Ser. Earth Environ. Sci. 2020, 546, 42048. [CrossRef]

17. Pu, L.; Shao, X.; Zhang, S.; Lei, G.; Li, Y. Plume dispersion behaviour and hazard identification for large quantities of liquid hydrogen leakage. Asia-Pacfic J. Chem. Eng. 2019, 14, e2299. [CrossRef]

18. Choi, J.; Hur, N.; Kang, S.; Lee, E.D.; Lee, K. A CFD simulation of hydrogen dispersion for the hydrogen leakage from a fuel cell vehicle in an underground parking garage. Int. J. Hydrog. Energy 2013, 38, 8084-8091. [CrossRef]

19. Shao, X.; Pu, L.; Li, Q.; Li, Y. Numerical investigation of flammable cloud on liquid hydrogen spill under various weather conditions. Int. J. Hydrog. Energy 2018, 43, 5249-5260. [CrossRef]

20. Hwang, J.; Yoon, D.; Choi, K.; Kim, Y.; Kim, L.H. 3D CFD analysis of the hydrogen releases and dispersion around storage facilities. Korean J. Chem. Eng. 2008, 25, 217-222. [CrossRef]

21. Afghan Haji Abbas, M.; Kheradmand, S.; Sadoughipour, H. Numerical study of the effect of hydrogen leakage position and direction on hydrogen distribution in a closed enclosure. Int. J. Hydrog. Energy 2020, 45, 23872-23881. [CrossRef]

22. Wang, Q.; Zhai, C.; Gong, J.; Wang, Z.; Jiang, J.; Zhou, Y. Analytical and numerical predictions of hydrogen gas flow induced by wall and corner leakages in confined space. Int. J. Hydrog. Energy 2020, 45, 6848-6862. [CrossRef]

23. Zhang, J.; Zhang, X.; Huang, W.; Dong, H.; Wang, T. Isentropic analysis and numerical investigation on high-pressure hydrogen jets with real gas effects. Int. J. Hydrog. Energy 2020, 45, 20256-20265. [CrossRef]

24. Mao, X.; Ying, R.; Yuan, Y.; Li, F.; Shen, B. Simulation and analysis of hydrogen leakage and explosion behaviors in various compartments on a hydrogen fuel cell ship. Int. J. Hydrog. Energy 2020. [CrossRef]

25. Nagase, Y.; Sugiyama, Y.; Kubota, S.; Saburi, T.; Matsuo, A. Prediction model of the flow properties inside a tube during hydrogen leakage. J. Loss Prevent. Proc. 2019, 62, 103955. [CrossRef]

26. Yassine, H.; Mourad, B.; Afif, E.; Ali, B.; Philippe, B.; Ftouh, K. Natural ventilation of hydrogen during a leak in a residential garage. Renew. Sustain. Energy Rev. 2015, 50, 810-818.

27. Yao, Q.; Zhu, H. Numerical simulation of hydrogen dispersion behaviour in a partially open space by a stabilized balancing domain decomposition method. Comput. Math. Appl. 2015, 69, 1068-1079. [CrossRef]

28. Li, Y.; Jiang, J.; Yu, Y.; Zhang, Q. Numerical simulation of dispersion and distribution behaviors of hydrogen leakage in the garage with a crossbeam. Simulation 2019, 95, 1229-1238. [CrossRef]

29. Wang, K.; Zhang, X.; Miao, Y.; He, B.; Wang, C. Dispersion and behavior of hydrogen for the safety design of hydrogen production plant attached with nuclear power plant. Int. J. Hydrog. Energy 2020, 45, 20250-20255. [CrossRef]

30. De Stefano, M.; Rocourt, X.; Sochet, I.; Daudey, N. Hydrogen dispersion in a closed environment. Int. J. Hydrog. Energy 2019, 44, 9031-9040. [CrossRef]

31. Li, F.; Yuan, Y.; Yan, X.; Malekian, R.; Li, Z. A study on a numerical simulation of the leakage and diffusion of hydrogen in a fuel cell ship. Renew. Sustain. Energy Rev. 2018, 97, 177-185. [CrossRef]

32. Malakhov, A.A.; Avdeenkov, A.V.; du Toit, M.H.; Bessarabov, D.G. CFD simulation and experimental study of a hydrogen leak in a semi-closed space with the purpose of risk mitigation. Int. J. Hydrog. Energy 2020, 45, 9231-9240. [CrossRef]

33. Qian, J.; Li, X.; Gao, Z.; Jin, Z. A numerical study of hydrogen leakage and diffusion in a hydrogen refueling station. Int. J. Hydrog. Energy 2020, 45, 14428-14439. [CrossRef]

34. Chapelle, D.; Hocine, A.; Carbillet, S.; Boubakar, M.L. Analysis of intermetallic swelling on the behavior of a hybrid solution for compressed hydrogen storage-Part II: Finite element method simulation. Mater. Des. 2012, 36, 459-469. [CrossRef]

35. Hussein, H.; Brennan, S.; Molkov, V. Dispersion of hydrogen release in a naturally ventilated covered car park. Int. J. Hydrog. Energy 2020, 45, 23882-23897. [CrossRef] 
36. Abdo, P.; Taghipour, R.; Huynh, B.P. Three-dimensional simulation of wind-driven ventilation through a windcatcher with different inlet designs. J. Therm. Sci. Eng. Appl. 2019, 12, 041008-1-041008-14. [CrossRef]

37. Ishimoto, J.; Sato, T.; Combescure, A. Computational approach for hydrogen leakage with crack propagation of pressure vessel wall using coupled particle and Euler method. Int. J. Hydrogen Energy 2017, 42, 10656-10682. [CrossRef]

38. Du, L.; Yuan, M.; Wei, H.; Xing, X.; Feng, D.; Liao, Y.; Chen, H.; Yang, D. Interconnected Pd nanoparticles supported on Zeolite-AFI for hydrogen detection under ultralow temperature. ACS Appl. Mater. Inter. 2019, 11, 36847-36853. [CrossRef]

39. Kazuo, M. Effects of the geometrical configuration of a ventilation system on leaking hydrogen dispersion and accumulation. Int. J. Hydrogen Energy 2009, 34, 9869-9878.

40. Liang, Z.; McKenna, A.; Clouthier, T.; David, R. Experimental study on accumulation of helium released into a semi-confined enclosure with distributed leaks. Int. J. Hydrogen Energy 2020. [CrossRef]

41. Zhao, M.; Huang, T.; Liu, C.; Chen, M.; Ji, S.; Christopher, D.M.; Li, X. Leak localization using distributed sensors and machine learning for hydrogen releases from a fuel cell vehicle in a parking garage. Int. J. Hydrog. Energy 2020, 46, 1420-1433. [CrossRef]

42. Cariteau, B.; Brinster, J.; Tkatschenko, I. Experiments on the distribution of concentration due to buoyant gas low flow rate release in an enclosure. Int. J. Hydrog. Energy 2011, 36, 2505-2512. [CrossRef] 